\title{
EL SEGURO DE RESPONSABILIDAD CIVIL Y LA JURISPRUDENCIA COLOMBIANA. EXAMEN DE LOS MÁS RECIENTES PRONUNCIAMIENTOS DE LA CORTE SUPREMA DE JUSTICIA*
}

\author{
LIABILITY INSURANCE POLICIES \\ AND COLOMBIAN JURISPRUDENCE. ANALYSIS \\ OF THE MOST RECENT DECISIONS OF THE \\ COLOMBIAN SUPREME COURT OF JUSTICE
}

MARÍA CRISTINA ISAZA POSSE**

\footnotetext{
* Conferencia dictada en el IV Congreso Internacional de Derecho Privado en la Facultad de Derecho de la Universidad Pontificia Bolivariana (UPB) los días 15 y 16 de octubre de 2019 en homenaje al Profesor "J. Efren Ossa G." en el centenario de su nacimiento. "Balance y proyecciones del derecho privado patrimonial: La responsabilidad civil y el seguro en la posmodernidad.

** Abogada Universidad Javeriana. Especialista y Magistra en Derecho de Seguros, Universidad Javeriana. Asesora y Consultora. Profesora Universitaria. Contacto: mcisaza@ isazaposse.com
} 
El tema se aborda de manera separada en cada uno de los distintos aspectos relacionados con el seguro de responsabilidad civil y la cobertura que se otorga mediante estos contratos de seguro.

1. En cuanto se refiere a la cobertura del lucro cesante y de los perjuicios extrapatrimoniales sufridos por la víctima:

El riesgo asegurable en el seguro de responsabilidad civil consiste en la posible aparición de un pasivo en el patrimonio del asegurado resultante de una obligación de indemnizar a un tercero por concepto de la responsabilidad civil que le sea imputable. Esta responsabilidad puede ser de naturaleza contractual o extracontractual.

De acuerdo con la tesis sostenida por la jurisprudencia y la doctrina, el alcance de la obligación de responsabilidad civil comprende los siguientes conceptos:

- Prevención

- Mitigación del peligro

- Indemnización

- Patrimonial

- Daño Emergente

- Lucro Cesante

- Extrapatrimonial

- Daño Moral

- Daño a la salud (Condiciones existencia)

- Derechos constitucionalmente tutelados

- Sanción

El seguro de responsabilidad civil tiene por objeto el pago de la indemnización que resulte a cargo del asegurado, e incluye también los costos del proceso que instaure el tercero damnificado en contra del asegurado o de la aseguradora. Los gastos en que incurra el asegurado para prevenir la generación del daño, para mitigar el peligro, así como los correspondientes a la sanción que resulte a su cargo, no son objeto de la cobertura otorgada bajo el seguro de responsabilidad civil. Tratándose de los gastos correspondientes a la prevención y mitigación del peligro, 
éstos podrían ser amparados mediante pacto expreso y a través de otra clase de cobertura, distinta de la otorgada bajo las pólizas de Responsabilidad civil.

La indemnización comprende los siguientes conceptos:

- Indemnización:

- Patrimonial

- Daño Emergente

- Lucro Cesante

- Extrapatrimonial

- Daño Moral

- Daño a la salud (Condiciones existencia)

- Derechos constitucionalmente tutelados

Si eliminamos de la cobertura el lucro cesante y los perjuicios extrapatrimoniales de la víctima, el amparo se reduciría únicamente al daño emergente, el cual en la gran mayoría de los casos es pagado por el Sistema de Seguridad Social. Lo anterior llevaría a una situación en la cual la cobertura del seguro resulta prácticamente inexistente.

Con el fin de tener una noción clara del alcance de estos dos conceptos, se incluyen los siguientes cuadros:

\section{CUADRO COMPARATIVO LUCRO CESANTE}

\begin{tabular}{|c|c|c|c|}
\hline INGRESOS & & CONSECUENCIA & LUCRO CESANTE FUTURO \\
\hline & $828.116(25 \%)$ & Muerto & $\$ 151^{\prime} .018 .810$ \\
\hline & & Inválido & $\$ 201: 470.665$ \\
\hline & $1.000 .000(25 \%)$ & Muerto & $\$ 182 ' .364 .319$ \\
\hline & & Inválido & $\$ 243^{\prime} .152 .425$ \\
\hline & $2.000 .000(25 \%)$ & Muerto & $\$ 364 \cdot .728 .637$ \\
\hline & & Inválido & $\$ 486 ' .304 .850$ \\
\hline & $5.000 .000(25 \%)$ & Muerto & $\$ 911 ' .821 .594$ \\
\hline & & Inválido & $\$ 1.215^{\prime} .762 .125$ \\
\hline & 10.000 .000 & Muerto & $\$ 1.4588^{\prime} .914 .550$ \\
\hline & & Inválido & $\$ 1.945^{\prime} .219 .400$ \\
\hline Edad de la victima & & 30 años & \\
\hline Género & & Masculino & \\
\hline Condición & & Válido & \\
\hline Vida probable (Res. 1555 julio 30 de 2010) & & 50.3 años $(604 \mathrm{~m})$ & \\
\hline
\end{tabular}




\section{PERJUICIOS EXTRAPATRIMONIALES \\ Máximos sugeridos}

\begin{tabular}{|c|c|c|c|}
\hline & CIVIL & $\begin{array}{l}\text { CONTENCIOSO } \\
\text { ADMINISTRATIVO }\end{array}$ & PENAL \\
\hline Daño moral & $\begin{array}{l}\$ 72 ' .000 .000 \\
\text { (Porredlamante) }\end{array}$ & $\begin{array}{l}100 S_{M M L V} \text { por reclamsnte } \\
\text { Regla general } \\
\text { Casos especiales }\end{array}$ & $\begin{array}{l}\text { 1.000 SMMLV } \\
\text { Todos reclamantes } \\
\text { Todo concepto extrapatrimonial }\end{array}$ \\
\hline $\begin{array}{l}\text { Alteración condiciones de } \\
\text { existencia } \\
\text { Daño a la salud }\end{array}$ & 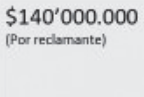 & $\begin{array}{l}100 \mathrm{SMMLV}_{\text {por reclamante }} \\
400 \mathrm{SMMLV}_{\text {por reclamante }}\end{array}$ & $\begin{array}{l}1.000 \text { SMMLV } \\
\text { Todos reclamsntes } \\
\text { Toda concepto extrapatrimonial }\end{array}$ \\
\hline $\begin{array}{l}\text { Daños a derechos o bienes } \\
\text { constitucionalmente protegidos }\end{array}$ & $\begin{array}{l}\$ 20^{\prime} .000 .000 \\
\text { (Porredlamante) }\end{array}$ & $\begin{array}{l}100 \text { SMMLV } \\
\text { Todos los reclamantes } \\
2018 \text { - para clu de los reclamantes }\end{array}$ & \\
\hline
\end{tabular}

Entre las decisiones recientes de la Corte Suprema de Justicia sobre este aspecto encontramos las siguientes:

Corte Suprema de Justicia. Sala Civil.

SC20950-2017.

Diciembre 12 de 2017.

Radicación: 05001-31-03-005-2008-00497-01.

Aprobado en sesión del 15 de agosto de 2017.

Magistrado ponente: Ariel Salazar Ramírez.

Corte Suprema de Justicia. Sala Civil.

SC002-2018.

Enero 12 de 2018.

Radicación: 11001-31-03-027-2010-00578-01.

Aprobado en sesión del 6 de septiembre de 2017.

Magistrado ponente: Ariel Salazar Ramírez.

Corte Suprema de Justicia. Sala Civil.

Junio 12 de 2018.

Radicación: 11001-31-03-032-2011-00736-01.

Aprobado en sala el 21 de febrero de 2018.

Magistrado ponente: Luis Armando Tolosa Villabona. 
Corte Suprema de Justicia. Sala civil

SC665-2019

Rad: 05001-31-03.016-2009-00005-01

Marzo 7 de 2019

Ponente: Octavio Augusto Tejeiro Duque

Corte Suprema de Justicia. Sala Civil.

Tutela. STC5902-2019.

Mayo 14 de 2019.

Rad:11001-02-03-000-2019-01191-00

Magistrado ponente: Luis Armando Tolosa Villabona.

Corte Suprema de Justicia. Sala Civil. Tutela.

STC10201-2019

Rad: 11001-02-03-000-2019-02406-00

Agosto $1^{\circ}$ de 2019

Magistrado ponente: Luis Armando Tolosa Villabona

En todas estas decisiones, previo el estudio del alcance de la cobertura otorgada bajo las pólizas de seguro de responsabilidad civil de cara a la obligación derivada de la responsabilidad civil, y tomando en consideración lo dispuesto por los artículos 1127 y 1088 del Código de Comercio, la Corte Suprema reitera lo inadecuado e improcedente de las exclusiones del lucro cesante y de los perjuicios extrapatrimoniales sufridos por la víctima, los cuales hacen parte de la obligación a cargo del asegurado causante del daño. La tesis se funda en que dichas exclusiones desnaturalizan el contrato de seguro de responsabilidad civil,

En contraposición a los anteriores y reiterados pronunciamientos de la corporación, en la siguiente sentencia de tutela proferida por la Sala Laboral de la Corte se confirmó la decisión que negó la indemnización del lucro cesante por parte de la aseguradora por estar expresamente excluido de la cobertura en la póliza de Responsabilidad Civil. 
Corte Suprema de Justicia. Sala Laboral. Tutela.

STL1322-2019

Rad: 82899

Enero 30 de 2019

Ponente: Clara Cecilia Dueñas Quevedo

2. En cuanto a la cobertura de la culpa grave del asegurado en la generación del daño:

Corte Suprema de Justicia. Sala Civil.

Referencia: 50001-31-03-008-2005-00425-01.

Julio 5 de 2012.

Aprobada el 28 de mayo de 2012

Magistrado ponente: Fernando Giraldo Gutiérrez.

Tratándose de un Seguro de Responsabilidad Civil profesional, la Corte estudia el tema del amparo de la culpa grave y la aparente contradicción del artículo 1127 del Código de Comercio con lo dispuesto en el artículo 1055 de la misma codificación. Concluye que en el supuesto de no estar expresamente excluida de la cobertura la culpa grave, ésta se encuentra cubierta por el seguro de responsabilidad civil, dejando claro que el dolo, en ningún caso es asegurable.

3. En cuanto se refiere al Amparo de Responsabilidad Civil Patronal que se otorga bajo las pólizas de seguro de Responsabilidad Civil Extracontractual y la viabilidad de la acumulación de las prestaciones derivadas de la seguridad social con la indemnización plena de perjuicios a cargo del patrono en los eventos de accidentes de trabajo:

Corte Suprema de Justicia. Sala Civil.

Julio 9 de 2012

Expediente:11001-3103-006-2002-00101-01

Ponente: Ariel Salazar Ramírez 
En esta sentencia se resuelve que es el juez quien en cada caso particular debe decidir sobre la procedencia de la acumulación de indemnizaciones.

Corte Suprema de Justicia. Sala Laboral.

Octubre 16 de 2013

Radicación 42433

Ponente: Ernesto Molina Monsalve

En un caso en el que el patrono no afilió al empleado al sistema de seguridad social y se encontraba probada la culpa patronal, se condena el patrono al pago de todo lo que hubiese pagado la ARL y adicionalmente, al pago de la indemnización plena de perjuicios por un accidente de trabajo.

Corte Suprema de Justicia. Sala Civil.

Enero 14 de 2015

Expediente:68001-3103-005-2007-00144-01

Ponente: Margarita Cabello Blanco

No procede subrogación de la ARL que paga la pensión de sobrevivientes contra el tercero civilmente responsable, tomando en consideración que se trata de obligaciones de distinta naturaleza. La obligación de la ARL es de naturaleza prestacional y tiene como causa la afiliación del empleado al Sistema, mientras que la obligación del responsable es de carácter indemnizatorio.

Corte Suprema de Justicia. Sala Laboral.

Agosto 15 de 2018

SL3387-2018

Rad: 63038

Ponente: Jimena Isabel Godoy Fajardo

La Corte acepta la compatibilidad del pago proveniente del SSS y la indemnización plena de perjuicios. En consecuencia, el patrono no puede 
descontar lo pagado por el SSS, pues dicho pago es objetivo, mientras que el pago de la indemnización plena por parte del patrono es subjetivo. Las Entidades del SSS tampoco pueden descontar lo pagado por el patrono como indemnización. Estudia el alcance del artículo 216 Código Sustantivo del Trabajo, concluyendo que no se trata de una doble indemnización del mismo perjuicio.

La dificultad se presenta frente al amparo de responsabilidad patronal que se incluye en las pólizas de seguro de responsabilidad civil, por cuanto el amparo, en términos generales, se encuentra definido de la siguiente manera:

La aseguradora cubre los perjuicios que cause el asegurado por muerte o lesiones personales de sus empleados como consecuencia directa de accidentes de trabajo.

La cobertura opera única y exclusivamente en exceso de las prestaciones laborales (Art. 216 CST), en exceso del SOAT y en exceso de cualquier otro seguro individual o colectivo de los empleados.

En consecuencia, el patrono tiene a su cargo un deducible equivalente a lo que pague la seguridad social o cualquier otro seguro.

4. En cuanto a las pólizas de seguro de responsabilidad civil expedidas bajo modalidad temporal Por Reclamación o Claims Made:

Corte Suprema de Justicia. Sala Civil.

Julio 18 de 2017.

Sentencia SC10300-2017

Radicación: 76001-31-03-001-2001-00192-01.

Magistrado ponente: Aroldo Wilson Quiroz Monsalvo.

Corte Suprema de Justicia. Sala Civil.

SC130-2018.

Radicación: 11001-31-03-031-2002-01133-01.

Febrero 12 de 2018.

Magistrado ponente: Aroldo Wilson Quiroz Monsalvo. 
En ambas sentencias se encuentran Aclaraciones y Salvamentos de voto de los magistrados Ariel Salazar Ramírez y Luis Armando Tolosa Villabona en las que dichas cláusulas son calificadas como abusivas, irrazonables, inequitativas, ilegales e inconstitucionales. Se afirma que se trataría de cláusulas nulas.

Contraloría General de la República.

Despacho del Contralor General.

Auto Número: ORD-80112-0161-2019.

Agosto 15 de 2019.

En un proceso de Responsabilidad fiscal, al estudiar la cobertura de una Póliza de Responsabilidad de Servidores Públicos, la Contraloría afirma que la Cláusula Claims Made es desproporcionada, ineficaz y no vinculante. Afirma que ésta no guarda relación con el riesgo, aplica la cobertura por ocurrencia y, de manera inexplicable, adiciona las sumas aseguradas correspondientes a la vigencia de varias pólizas.

Nota febrero 3 de 2010: esta decisión fue revocada por la Contraloría General de la República mediante Resolución Ordinaria $N^{\circ} O R D$ 80112-0737. Noviembre 18 de 2019.

5. En lo relativo a la prescripción, encontramos:

Corte Suprema de Justicia. Sala Civil.

Mayo 6 de 2016.

Ref: 54001-31-03-004-2004-00032-01

MP: Luis Armando Tolosa Villabona.

Tratándose del seguro de RC bajo modalidad ocurrencia, señala la diferencia existente entre acción directa de la víctima contra la aseguradora y el llamamiento en garantía que hace el asegurado a la aseguradora dentro del proceso. Indica que el término de prescripción aplicable a cada una de ellas es diferente y corre desde momentos distintos. Reitera que el término de prescripción de la acción directa es el de la prescripción extraordinaria previsto en el artículo 1081 del Código de Comerio, de cinco (5) años. 
TRIBUNAL SUPERIOR DEL DISTRITO JUDICIAL SALA CIVIL DE DECISION

MAG. SUSTANCIADOR: DR. FLAVIO EDUARDO CÓRDOBA FUERTES

Santiago de Cali, febrero 12 de 2019

Rad. No. 76001-31-03 - 009 - 2012 - 00132 - 01 (9068)

“... toda vez que una nueva mirada del tema objeto de controversia, permite a esta Sala concluir que formulada al asegurado por la víctima la reclamación extrajudicial de la indemnización y enterada de esta situación la aseguradora, la prescripción ordinaria que allí empezó a correr se suspende hasta tanto ese asegurado sea notificado de la demanda judicial que inicie en su contra la víctima, momento a partir del cual el cómputo de ese término prescriptivo se reanuda pues para ese momento ya es de su cargo formular y notificar oportunamente el respectivo llamamiento en garantía.(2). (2) Así lo decidió esta misma Sala de Decisión en sentencia del 7 de febrero de 2019 con ponencia del doctor Julián Alberto Villegas Perea. Rad. 0150016-00006-01 (3837).

"No obstante, lo que sí podemos decir es que enterada la compañía de seguros de la reclamación extrajudicial de la víctima, no es posible considerar por claros principios de justicia e igualdad entre los contratantes, que la prescripción continúe corriendo para el asegurado en espera de que la víctima decida formular la demanda judicial."

Se trata de una interpretación tendiente a favorecer los derechos del asegurado bajo una póliza de seguro de responsabilidad civil bajo modalidad ocurrencia, en la que al tenor de lo dispuesto por el artículo 1131 del Código de Comercio la prescripción correspondiente a la acción del asegurado contra la aseguradora corre desde el momento en que víctima formula su pretensión judicial o extrajudicial.

6. En lo referente a los casos en que la aseguradora llamada en garantía es condenada como solidariamente responsable al pago de la indemnización a la víctima:

Corte Suprema de Justicia, Sala Civil.

STC2491-2019

Rad:11001-02-03-000-2019-00433-00

Marzo 1 de 2019

Ponente: Margarita Cabello Blanco 
Aclara la Corte que la aseguradora llamada en garantía no es solidariamente responsable. Ella no es causante del daño. Responde por una obligación propia en los términos y condiciones establecidos en el contrato de seguro celebrado.

7. Seguro de responsabilidad civil extracontractual en la Contratación Estatal:

Consejo de Estado. Sección Tercera.

Subsección A.

Rad: 11001-03-26-000-2009-00047-00 (36860).

Junio 14 de 2019.

Consejero ponente: Carlos Alberto Zambrano Barrera.

Resuelve la demanda de Nulidad del Decreto 4828 de 2008, que reglamentó el tema de las Garantías que deben prestar los contratistas en la contratación estatal, entre las que se cuenta la Póliza de Seguro de Responsabilidad Civil Extracontractual. Define el Consejo de Estado el alcance de la Potestad Reglamentaria del Gobierno, aclarando que dicha facultad no fue extralimitada en este caso. 
